\title{
Influência de diferentes composições de substratos na propagação vegetativa de Gypsophila no litoral cearense ${ }^{1}$
}

\author{
Influence of different compositions of substrates on the vegetative propagation of \\ Gypsophila along the Ceará coastline
}

\author{
Aurilene Araújo Vasconcelos ${ }^{2 *}$, Renato Innecco $^{2}$ e Sérgio Horta Mattos $^{2}$
}

\begin{abstract}
RESUMO - A espécie Gypsophila paniculata L., é conhecida popularmente como branquinha ou mosquitinho, pertence à família Caryophyllaceae e tem sido cultivada comercialmente como flor de corte. Sua propagação se dá através de mudas (estacas enraizadas). Este trabalho teve como objetivo avaliar o pó de coco e a casca de arroz carbonizada, isolados ou em misturas como substratos visando um bom enraizamento de estacas de Gypsophila paniculata. O trabalho foi conduzido na Fazenda Plurinvest Agropecuária e Turismo Ltda, Trairi-CE. O delineamento experimental foi inteiramente casualisado, sendo oito tratamentos e quatro repetições (10 estacas cada). Os tratamentos foram: pó de coco; pó de coco solarizado; pó de coco tratado com fungicida (Propamocarbe); pó de coco solarizado e tratado com fungicida; casca de arroz carbonizada; casca de arroz carbonizada tratada com fungicida; casca de arroz carbonizada + pó de coco solarizado; casca de arroz carbonizada + pó de coco solarizado e a mistura tratada com fungicida. Após 24 dias, em casa de vegetação com sombrite a 50\% e sob irrigação por nebulização, foi avaliada matéria seca radicular $(\mathrm{g})$, comprimento da maior raiz $(\mathrm{cm})$ e comprimento da parte aérea $(\mathrm{cm})$. Para as variáveis matéria seca da raiz, comprimento de raiz e comprimento de parte aérea, os substratos casca de arroz carbonizada (0,099 g; 5,50 cm e 6,2 cm respectivamente) e casca de arroz carbonizada + pó de coco solarizado (0,097 g; $5,40 \mathrm{~cm} \mathrm{e} 6,1 \mathrm{~cm}$ respectivamente) proporcionaram os melhores resultados na propagação vegetativa da Gypsophila paniculata.
\end{abstract}

Palavras-chave: Gipsofila. Plantas-propagação por estaquia. Substrato.

\begin{abstract}
The species Gypsophila paniculata L., popularly known as baby's breath, branquinha or mosquitinho, belongs to the Caryophyllaceae family and has been grown commercially for sale as a cut flower. Its propagation is by means of rooted cuttings. The objective of this study was to evaluate coir dust and charred rice husks as substrates, both separate and in mixture, with an aim to the good rooting of Gypsophila paniculata cuttings. The work was caried out at the Fazenda Plurinvest Agropecuária e Turismo Ltda farm, located in Trairi, Ceará. The experimental design was completely randomized, with eight treatments and four replications (of 10 cuttings each). The treatments were: coir dust; solarised coir dust; coir dust treated with fungicide (Propamocarbe); solarised coir dust treated with fungicide; charred rice husks; charred rice husks treated with fungicide; charred rice husks and solarised coir dust; charred rice husks and solarised coir dust, the mixture treated with fungicide. After 24 days in a greenhouse in 50\% shade and under irrigation by misting, the root dry-matter (g), longest root length $(\mathrm{cm})$ and shoot length $(\mathrm{cm})$ were evaluated. For the root dry-matter, root length and shoot length variables, the substrates of charred rice husks $(0.099 \mathrm{~g}, 5.50 \mathrm{~cm}$ and $6.2 \mathrm{~cm}$ respectively) and charred rice husks with solarised coir dust $(0.097 \mathrm{~g}, 5.40$ $\mathrm{cm}$ and $6.1 \mathrm{~cm}$ respectively) gave the best results for the vegatative propagation of Gypsophila paniculata.
\end{abstract}

Key words: Gypsophila. Plants by cutting. Substrate.

\footnotetext{
*Autor para correspondência

${ }^{1}$ Recebido para publicação em 08/02/2011; aprovado em 05/03/2012

Parte da Tese de Doutorado do primeiro autor, apresentada ao Programa de Pós-Graduação em Agronomia/Fitotecnia/CCA/UFC

${ }^{2}$ Departamento de Fitotecnia/CCA/UFC, Av. Mister Hull 1977, Campus do Pici, Fortaleza-CE, Brasil, 60.356-000,aurilenevasconcelos@ hotmail.com, innecco@ufc.br, horta@ufc.br
} 


\section{INTRODUÇÃO}

A Gypsophila paniculata L., é uma angiosperma, conhecida popularmente como branquinha ou mosquitinho, pertence à família Caryophyllaceae, têm sido cultivada comercialmente como flor de corte para utilização na confecção de arranjos e buquês (HIRANAKA; BARONE; MINAMI, 2005; RIOS, 2004; SÃO JOSÉ, 2004; TAKANE, 1997; WOLCAN; RONCO; LORI, 2007).

É considerada uma das principais flores de corte no Brasil (RIOS, 2004; SÃO JOSÉ, 2004), sendo o terceiro produto mais comercializado na CEAGESP e um dos dez mais vendidos no Veiling de Holambra-SP e nos onze principais países produtores de flores e plantas ornamentais (RIOS, 2004).

Os maiores produtores brasileiros são Minas Gerais, Rio de Janeiro, São Paulo, Paraná, Santa Catarina e Rio Grande do Sul, sendo que São Paulo movimenta $70 \%$ da produção (BOSA et al., 2003a).

Comercialmente, a propagação de Gypsophila ocorre através de cultura de tecidos ou por enraizamento de estacas de ponteiros (SÃO JOSÉ, 2004). No entanto, o processo de enraizamento de estacas é complexo incluindo fatores fisiológicos, bioquímicos e biológicos que interagem com os fatores ambientais (BOSA et al., 2003b).

Substrato é o meio de desenvolvimento do sistema radicular, servindo de suporte e podendo ser fonte de nutrientes. Pode ser formado por um único material ou pela mistura de dois ou mais materiais como: fibra de coco, casca de pínus ou casca de arroz carbonizada (TAKANE et al., 2009, 2010; YAMAMOTO et al., 2009). Os resíduos agrícolas representam alternativas na substituição aos substratos comerciais como xaxim (Dicksonia sellowiana), cuja utilização está proibida.

Segundo Peixoto et al. (2006), os resíduos agrícolas mais facilmente disponíveis no Ceará são: pó de coco seco, esterco bovino, casca de arroz carbonizada e bagana de carnaúba, que têm promovido resultados positivos no desenvolvimento de plântulas de diversas culturas.

Os substratos, à base de material orgânico, devem apresentar as seguintes características: $\mathrm{pH}$ na faixa de 5,0 a 5,5, baixa salinidade, lenta decomposição e permitir o desenvolvimento de microrganismos desejáveis (YAMAKAMI et al., 2006).

Os substratos provenientes do coco são totalmente biodegradáveis e não poluentes (OLIVEIRA; HERNANDEZ; ASSIS JÚNIOR, 2008; SILVA JÚNIOR; GOMES; MENDES FILHO, 2006). Apresentam baixa condutividade elétrica e baixos teores de nutrientes e sais, portanto, seu uso como substrato, deverá ser em mistura com materiais mais ricos em nutrientes ou com suplementação de nutrientes (KANASHIRO et al., 2008; SILVA JÚNIOR; GOMES; MENDES FILHO, 2006).
A casca de arroz carbonizada tem sido mais utilizada como substrato, pois é estável física e quimicamente e mais resistente à decomposição (MELO; BORTOLOZZO; VARGAS, 2006), possui baixa densidade; leve e porosa permitindo boa aeração e drenagem; tem volume constante (seca ou úmida); livre de plantas daninhas, nematóides e patógenos, pois é esterilizada durante a carbonização (ROESSLER et al., 2011).

O Estado do Ceará é dependente de São Paulo para a produção de Gypsophila, pois as mudas desta espécie são produzidas nesse Estado, o que aumenta os custos de produção devido ao frete, reduzindo a concorrência com a flor importada de São Paulo. Assim, se torna necessário despertar o interesse para a produção de mudas no Ceará. Sendo necessário definir um substrato de fácil aquisição e baixo custo que promova um bom desenvolvimento destas mudas nas condições ambientais cearenses.

Portanto, este trabalho teve como objetivo avaliar o pó de coco e a casca de arroz carbonizada, isolados ou em misturas visando um bom enraizamento de estacas e desenvolvimento de mudas de Gypsophila paniculata.

\section{MATERIAL E MÉTODOS}

Os experimentos foram desenvolvidos na Fazenda Plurinvest Agropecuária e Turismo Ltda, localizada na Lagoa das Almécegas, Trairi-CE, aproximadamente $130 \mathrm{~km}$ de Fortaleza, Litoral Norte do Ceará, situada a $27 \mathrm{~m}$ de altitude, latitude de 302 '33" Sul, longitude de 39¹2'06" Oeste, temperatura média de $26^{\circ} \mathrm{C}$, umidade relativa média $82 \%$, insolação de $2.800 \mathrm{~h}$ ano $^{-1} \mathrm{e}$ precipitação de $1.300 \mathrm{~mm}^{2} \mathrm{ano}^{-1}$.

$\mathrm{O}$ delineamento experimental foi inteiramente casualizado, constando de oito tratamentos e quatro repetições (10 estacas cada). Os experimentos foram constituídos dos seguintes substratos: Pó de coco (PC); Pó de coco solarizado (PCS); Pó de coco tratado com fungicida (PCF); Pó de coco solarizado e tratado com fungicida (PCSF); Casca de arroz carbonizada (CAC); Casca de arroz carbonizada tratada com fungicida (CACF); Casca de arroz carbonizada + Pó de coco solarizado (CAC+PCS); (Casca de arroz carbonizada + Pó de coco solarizado) tratados com fungicida (CAC+PCS)F.

As variáveis analisadas foram peso da matéria seca das raízes (g), comprimento de raiz ( $\mathrm{cm}$ ) e comprimento de parte aérea $(\mathrm{cm})$.

Nas misturas de substrato foi utilizada a proporção de 1:1, o fungicida utilizado foi um Propamocarbe na dosagem de $0,722 \mathrm{~g} \mathrm{~L}^{-1}$, e para a obtenção da solarização do pó de coco, o mesmo foi umedecido e disposto em uma 
camada de aproximadamente $5 \mathrm{~cm}$ de espessura em sacos transparentes, e exposta aos raios solares por cinco dias consecutivos, sobre piso de cimento.

As estacas foram obtidas de plantas matrizes selecionadas de acordo com as seguintes características: livre de pragas e doenças e melhor vigor. A coleta das estacas se iniciou às $6 \mathrm{~h} 30 \mathrm{~min}$, considerando-se que neste horário o clima é mais ameno e, as plantas encontram-se mais tenras (JESUS, 2007; LOGES, et al., 2005). Com este procedimento garante-se que os ponteiros colhidos possuam melhor qualidade e menor estresse hídrico devido às suas células estarem com a máxima capacidade de retenção de água, característica que melhora os índices de enraizamento das estacas (JESUS, 2007), e facilita a coleta das mesmas. A obtenção das estacas foi através da quebra manual do ponteiro, sendo padronizadas com $5 \mathrm{~cm}$ de comprimento. Não foi utilizado material cortante (estilete ou tesoura de poda) para manter a integridade das estacas e também para evitar a transmissão de várias doenças tanto para as mudas quanto para as plantas matrizes.

As estacas coletadas foram provenientes de brotações em estado vegetativo característico, não sendo selecionados ponteiros estiolados. Estacas de ramos estiolados podem induzir a floração precoce, o que acarretaria em crescimento vegetativo insuficiente não se obtendo o tamanho de haste desejado.

À medida que as estacas iam sendo coletadas, foram separadas em pacotes de 50 unidades em papel jornal umedecidos para evitar a perda de água. Depois da coleta as estacas foram levadas para casa de vegetação com tela sombrite a 50\%, tratadas com AIB na concentração de 2.000 ppm e plantadas em bandejas de polipropileno de 200 células, previamente preparadas com os substratos (tratamentos).

As mudasforammantidas sobirrigaçãopornebulização a cada duas horas durante o dia, e aos 24 dias após o plantio das estacas (ponteiros), retiraram-se as mudas das bandejas, juntamente com os torrões, os quais foram imersos em água e dissolvidos até a obtenção das raízes limpas, fez-se a medição do comprimento da parte aérea e da maior raiz e em seguida separou-se a parte aérea das raízes e estas foram colocadas para secar em estufa de ventilação forçada a $80{ }^{\circ} \mathrm{C}$ por 24 horas. Em seguida, foi realizada a pesagem da massa seca (MS) radicular. Os resultados foram submetidos à análise de variância utilizando o sistema de análise estatística SANEST (ZONTA; MACHADO, 1984), e as médias foram comparadas pelo teste de Tukey ao nível de $5 \%$ de probabilidade.

\section{RESULTADOS E DISCUSSÃO}

Na Tabela 6, através da análise de variância, observase que houve diferenças altamente significativas para os tratamentos aplicados ao enraizamento e desenvolvimento de estacas de ponteiro de Gypsophila paniculata.

Com relação à variável da matéria seca das raízes, ficou evidenciado que os melhores tratamentos foram casca de arroz carbonizada $(\mathrm{CAC}=0,099 \mathrm{~g})$ e casca de arroz carbonizada mais pó de coco solarizado $(\mathrm{CAC}+\mathrm{PCS}=0,097 \mathrm{~g})$, os quais diferenciaram-se estatisticamente dos tratamentos pó de coco $(\mathrm{PC}=0,042 \mathrm{~g})$ e pó de coco com fungicida ( $\mathrm{PCF}=0,051 \mathrm{~g}$ ) (Figura 1).

O segundo melhor tratamento foi o substrato casca de arroz carbonizada + pó de coco com fungicida (CAC + $\mathrm{PCSF}=0,085 \mathrm{~g}$ ) (Propamocarbe), o qual se diferenciou significativamente de PC $(0,042 \mathrm{~g})$ (Figura 1).

Enquanto os demais tratamentos comportaramse semelhantemente, CACF, PCS e PCSF apresentaram tendência a serem superiores aos PC e PCF (Figura 1).

Acredita-se que os resultados referentes aos substratos com CAC estejam relacionados com a inteiração da freqüência de irrigação $\mathrm{x}$ drenagem do substrato, que garantiu a manutenção da umidade para as raízes sem comprometer a aeração das mesmas. Semelhantes resultados foram encontrados por Bosa et al., (2003a), que trabalhando com diversos substratos (casca de arroz carbonizada (CAC) e cinco substratos comerciais da Empresa Turfa Fértil-SC, Horta (casca de pinus + turfa), Jardim (casca de pinus + turfa), Ornamental (casca de

Tabela 1 - Resumo da análise de variância para médias de eficiência dos tratamentos nas variáveis peso da matéria seca de raiz (PMSR), comprimento da maior raiz (CR) e comprimento da parte aérea (CPA) de mudas de Gipsophila paniculata. Trairi-CE, 2009

\begin{tabular}{lcccc}
\hline \multirow{2}{*}{ Causas da variação } & G. L. & PMSR $(\mathrm{g})$ & Q. M. & CR $(\mathrm{cm})$ \\
\cline { 3 - 5 } & & $0,0018187^{* *}$ & $4,6778595^{* *}$ & $0,6871006^{* *}$ \\
Tratamentos & 7 & 0,0003263 & 0,0962494 & 0,0255202 \\
Resíduo & 24 & 25,37 & 7,59 & 2,90 \\
C. V. $(\%)$ & & &
\end{tabular}

** Teste de Tukey a $1 \%$ 
Figura 1 - Matéria seca de raízes das mudas de Gypsophila paniculata cv. Golan, em oito tipos de substratos. PC (pó de coco), PCSF (pó de coco solarizado com fungicida), PCF (pó de coco com fungicida), PCS (pó de coco solarizado), CAC (casca de arroz carbonizada), CACF (casca de arroz carbonizada com fungicida), CAC + PCS (casca de arroz carbonizada + pó de coco solarizado) e CAC + PCSF (casca de arroz carbonizada + pó de coco solarizado com fungicida). Trairi-CE, 2009

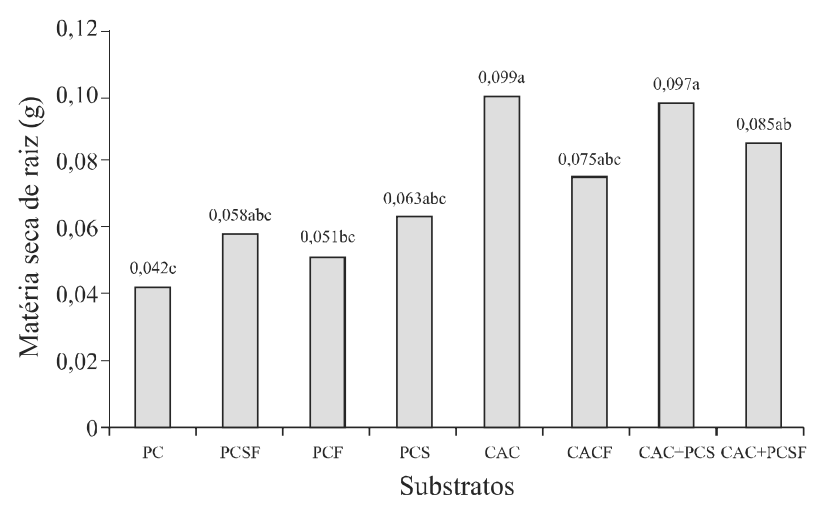

pinus + turfa + sílica), $\mathrm{FE}_{1}$ (perlita + turfa) e $\mathrm{FE}_{4}$ (casca de pinus + perlita + turfa), em crescimento de mudas de Gypsophila, verificaram que a CAC promoveu um aumento da massa seca de raízes nos primeiros 16 dias após o plantio, os autores relacionaram esses resultados ao elevado volume de aeração e maior drenagem desse substrato.

Sorace et al. (2009), também avaliaram diversos substratos - xaxim desfibrado - (testemunha); casca de arroz carbonizada; fibra de coco; casca de pínus; casca de pínus + fibra de coco (1:1); casca de arroz + fibra de coco (1:1); casca de arroz carbonizada + casca de pínus (1:1); casca de pínus + casca de arroz carbonizada + fibra de coco (1:1:1)) no desenvolvimento do híbrido de Cattleya intermedia x Hadrolaelia purpurata, e verificaram que para o desenvolvimento radicular, o substrato que mais se assemelhava ao xaxim foi a mistura de casca de arroz carbonizada + casca de pínus e o que menos se assemelhou foi o substrato fibra de coco.

Nos substratos PC $(0,042 \mathrm{~g})$ e PCF $(0,051 \mathrm{~g})$ se obteve os menores valores de matéria seca de raiz. Acredita-se que esses resultados estejam relacionados a uma maior retenção de umidade e pouca aeração, o que pode ter favorecido o desenvolvimento de microrganismos, pois no substrato PC se obteve o menor índice de enraizamento. Enquanto no PCF, a ação do fungicida pode não ter sido suficiente para o controle dos microrganismos ou pode ter contribuído para o efeito negativo deste tratamento. De acordo com Coutinho (2006) as doenças de solo estão associadas à umidade elevada e a altas temperaturas, condições observadas neste ensaio. Brondani et al. (2009), também não conseguiram bons resultados com a fibra de coco, ao trabalharem com estaquia de erva-mate, eles também associaram os maus resultados à alta umidade do ambiente.

Porém, Lima et al. (2008) e Pio et al. (2005), ao trabalharem com estacas de espinheira-santa e estacas herbáceas de figueiras, respectivamente, verificaram que a fibra de coco favoreceu o enraizamento das estacas. Yamamoto et al. (2009), recomendam a fibra de coco para cultivo de Miltonia regnellii x Oncidium concolor, em substituição ao xaxim.

Vale salientar que as condições ambientais e o tipo de material vegetal utilizado, podem ter interferido nos resultados, tanto neste experimento, quanto nos trabalhos citados.

No que se refere ao comprimento de maior raiz, os melhores resultados foram com os substratos CAC $(5,50 \mathrm{~cm}), \mathrm{CAC}+\mathrm{PCS}(5,40 \mathrm{~cm})$ e CAC + PCSF $(5,03$ $\mathrm{cm})$, os mesmos não se diferenciaram estatisticamente (Figura 2). Resultados semelhantes foram encontrados por Araújo et al. (2007) que constataram um dos maiores comprimentos de raiz na CAC, quando a compararam outros substratos (brita, fibra de piaçava e xaxim desfibrado) no crescimento de orquídeas. Isso porque a CAC possui uma baixa retenção de água, em função de sua alta porosidade o que proporciona uma boa relação entre água e ar, assim favorecendo o desenvolvimento das raízes.

O segundo melhor tratamento foi o CACF (Figura 2), o qual diferenciou significativamente dos demais substratos

Figura 2 - Comprimento da maior raiz de estacas de Gipsophila paniculata. cv. Golan, em oito tipos de substratos. PC (pó de coco), PCSF (pó de coco solarizado com fungicida), PCF (pó de coco com fungicida), PCS (pó de coco solarizado), CAC (casca de arroz carbonizada), CACF (casca de arroz carbonizada com fungicida), CAC + PCS (casca de arroz carbonizada + pó de coco solarizado) e CAC + PCSF (mistura de casca de arroz carbonizada + pó de coco solarizado + fungicida). Trairi-CE, 2009

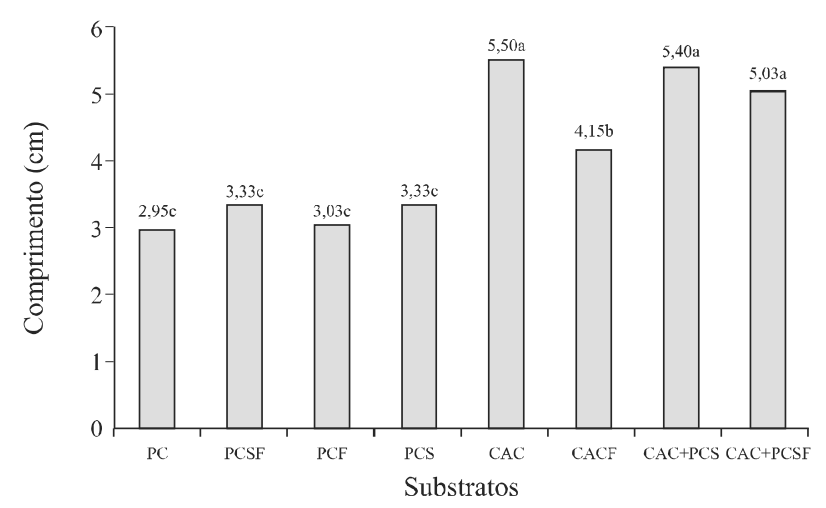


sendo, superior a PC, PCSF, PCF, PCS, e inferior a CAC, CAC + PCS e CAC + PCSF. Evidenciando-se que a associação da CAC com o fungicida utilizado causou efeito negativo no crescimento radicular de Gipsophila paniculata.

Os substratos contendo apenas PC com ou sem tratamento (solarização ou fungicida), foram os que apresentaram os menores crescimentos de raiz, e novamente se associou esses resultados a grande retenção de água desse substrato quando utilizado puro. Resultados semelhantes foram encontrados por Kanashiro et al. (2008), que constataram menor produção de matéria seca de raiz no substrato fibra de coco e associaram estas observações à alta relação C/N. Outros autores como Lima et al. (2005), trabalhando com progênies de acerola, constataram que nos substratos contendo pó de coco houve uma redução de $15 \%$ na emissão de primórdios radiculares. Estes, por sua vez, associaram os resultados aos elevados teores de tanino e sódio encontrados neste substrato, porém, o mesmo não se pode afirmar neste trabalho, pois o substrato utilizado foi lavado diariamente durante 15 dias antes de ser utilizado.

Na variável comprimento de parte aérea (Figura 3), os melhores tratamentos foram CAC $(6,2 \mathrm{~cm})$ e CAC + PCS $(6,1 \mathrm{~cm})$, os quais se diferenciaram estatisticamente dos demais tratamentos (Figura 3). Evidenciando assim, que CAC e a mistura desta com PCS (1:1) é a melhor composição de substratos, entre os aqui comparados, para o desenvolvimento de estacas de Gypsophila. Esses resultados provavelmente foram devidos às características físicas do substrato CAC, que devido à sua alta porosidade, permitiu boa relação água e ar, tanto na composição de $100 \%$ quanto de $50 \%$ (+ PCS) e consequentemente melhor desenvolvimento das plantas. Devido tanto às características físicas como as químicas, esse substrato tem sido recomendado para o cultivo de orquídeas em substituição ao xaxim (ARAÚJO et al., 2007).

$\mathrm{O}$ segundo melhor tratamento foi $\mathrm{CAC}+\mathrm{PCSF}$ $(5,6 \mathrm{~cm})$, o qual foi inferior ao CAC e CAC + PCS e superior aos PC $(5,2 \mathrm{~cm})$ e PCF $(5,2 \mathrm{~cm})$. Os demais tratamentos foram estatisticamente iguais (Figura 3).

Todos os substratos contendo somente PC independentemente da desinfecção (solarização ou aplicação de fungicida) proporcionaram os mesmos resultados no crescimento de parte aérea das estacas (Figura. 3). Porém os substratos CAC e CAC + PCS influenciaram negativamente no crescimento dessas plantas quando foi adicionado fungicida. Essas verificações podem estar relacionadas à estabilidade química da CAC (MELO et al., 2006), pois quando se utilizou fungicida no PC (100\%) não houve alteração no crescimento das plantas. Além disso, alguns produtos utilizados normalmente na agricultura podem causar
Figura 3 - Comprimento da parte aérea das mudas de Gipsophila paniculata. cv. Golan, em oito tipos de substratos. PC (pó de coco), PCSF (pó de coco solarizado + fungicida), PCF (pó de coco com fungicida), PCS (pó de coco solarizado), CAC (casca de arroz carbonizada), CACF (casca de arroz carbonizada com fungicida), CAC+PCS (casca de arroz carbonizada + pó de coco solarizado) e CAC+PCSF (casca de arroz carbonizada + pó de coco solarizado + fungicida). Trairi-CE, 2009

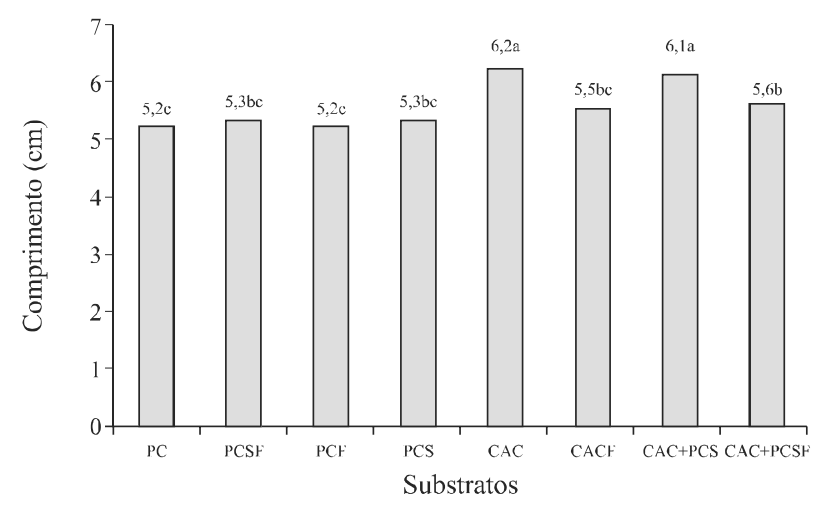

toxidez aos vegetais, como efeito fitotóxico por ácido indol butírico (AIB) no enraizamento de begônia observado por Fukasawa et al. (2011).

Quanto ao PC, Silva Júnior, Gomes e Mendes Filho (2006), no estudo com meloeiro, testaram diversas composições de substratos (solo, pó de coco, solo $+10 \%$ de pó de coco, solo $+20 \%$ de pó de coco, solo $+40 \%$ de pó de coco, solo $+60 \%$ de pó de coco, solo $+80 \%$ de pó de coco) e obtiveram os melhores resultados para o desenvolvimento das mudas na composição de $20 \%$ de pó de coco. Esses resultados podem ter sido influenciados pela composição física e química do substrato, que na composição de $20 \%$ ficaram mais balanceadas.

Peixoto et al. (2006), também trabalharam com diversos substratos (solo + pó de coco, solo + esterco de bovino, solo + bioadubo) no desenvolvimento de Opuntia ficus-indica após micropropagação in vitro, verificaram que o pó de coco influenciou negativamente o crescimento desta espécie, e associaram os resultados à alta retenção de umidade e à deficiência nutricional desse substrato.

Porém, Yamakami et al. (2006) e Yamamoto et al. (2009), recomendama fibra de coco paracultivo de bromélia (Aechmea fasciata), Cattleya labiata x Cattleya forbesii e Miltonia regnellii x Oncidium concolor, respectivamente, em substituição ao xaxim. E Oliveira, Hernandez e Assis Júnior (2008), conseguiram maior velocidade de emergência de plântulas de berinjela utilizando pó de coco verde lavado, no entanto, constataram melhor crescimento das plântulas no substrato, pó de coco seco. 
Diantedoexposto, verifica-sequeodesenvolvimento das plantas depende da composição física e química do substrato, da fisiologia da espécie, da presença de algum componente tóxico e do microclima local.

\section{CONCLUSÃO}

A casca de arroz carbonizada e a mistura de casca de arroz carbonizada + pó de coco solarizado podem ser utilizados como substratos para a propagação vegetativa de Gypsophila paniculata cv. Golan.

\section{REFERÊNCIAS}

ARAÚJO, A. et al. Substratos alternativos ao xaxim e adubação de plantas de orquídea na fase de Aclimatização. Ciência Rural, v. 37, n. 02, p. $569-571,2007$.

BOSA, N. et al. Crescimento de mudas de gipsofila em diferentes substratos. Horticultura Brasileira, v. 21, n. 03, p. 514-519, 2003 a.

BOSA, N. et al. Avaliação do crescimento de Gypsophila paniculata durante o enraizamento in vitro. Horticultura Brasileira, v. 21, n. 03, p. 510-513, 2003 b.

BRONDANI, G. E. et al. Composições de substratos e ambientes de enraizamento na estaquia de ilex paraguariensis a. St.-hil. Revista Floresta, v. 39, n. 01, p. 41-49, 2009.

COUTINHO, L. N. Doenças fúngicas de solo em plantas ornamentais. In: REUNIÃO ITINERANTE DE FITOSSANIDADE DO INSTITUTO BIOLÓGICO - FLORES E ORNAMENTAIS, 15., 2006, Holambra. Anais... Holambra: Instituto Biológico, 2006. p. 50- 60.

FUKASAWA, S. T. et al. Efeito da Aplicação de IBA no Enraizamento de Begônia. Disponível em: <http://www. abhorticultura.com.br/biblioteca/arquivos/Download/ Biblioteca/ 44_521.pdf>. Acesso em: 26 jan. 2011.

HIRANAKA, N.; BARONE, F. P.; MINAMI, K. Produção de Gypsophila. Piracicaba: ESALQ, 2005. 22 p. (Série Produtor Rural, 28)

JESUS, N. Avaliação de progênies de longan. 2007. 89 f. Tese (Doutorado em Produção Vegetal) - Faculdade de Ciências Agrárias e Veterinárias - Universidade Estadual Paulista "João de Mesquita Filho", Jaboticabal, 2007.

KANASHIRO, S. et al. Substratos alternativos ao xaxim na produção de bromélia ornamental. Pesquisa Agropecuária Brasileira, v. 43, n. 10, p. 1319-1324, 2008.

LIMA, D. M. et al. Substratos e auxinas no enraizamento de estacas caulinares de espinheira-santa. Scientia Agraria, v. 9, n. 01, p. 85-89, 2008.

LIMA, R. L. S. Enraizamento de estacas caulinares de acerola em função da composição do substrato. Semina: Ciências Agrárias, v. 26, n. 01, p. 27-32, 2005.
LOGES, V. et al. Colheita, pós-colheita e embalagem de flores tropicais em Pernambuco. Horticultura Brasileira, v. 23, n. 03, p. 699-702, 2005.

EMPRESA BRASILEIRA DE PESQUISA AGROPECUÁRIA. Produção de morangos no sistema semihiidropônico. In: MELO, G. W. B.; BORTOLOZZO, A. R.; VARGAS, L. Substratos. 2006. (Embrapa Uva e Vinho, 15) Disponível em: <http://sistemasdeproducao.cnptia.embrapa. br/FontesHTML/Morango/MorangoSemiHidroponico/ substratos.htm>.Acesso em: 14 jan. 2011.

OLIVEIRA, A., B.; HERNANDEZ, F. F. F.; ASSIS JÚNIOR, R. N. Pó de coco verde, uma alternativa de substrato na produção de mudas de berinjela. Revista Ciência Agronômica, v. 39, n. 01, p. 39-44, 2008.

PEIXOTO, M. J. A. et al. Desenvolvimento de Opuntia ficus-indica (L.) Mill., em diferentes substratos, após micropropagação in vitro. Acta Scientiarum. Animal Sciences, v. 28, n. 01, p. 17-20, 2006.

PIO, R. et al. A. Substratos no enraizamento de estacas herbáceas de figueira oriundas da desbrota. Ciência e Agrotecnologia, v. 29, n. 03, p. 604-609, 2005.

RIOS, J. F. Micropropagação de Gypsophila paniculata pela cultura de segmentos nodais e calogênese a partir de segmentos foliares. 2004. 36 f. Dissertação (Mestrado em Produção Vegetal) - Universidade Federal do Paraná, Curitiba, 2004.

ROESSLER, L. F. et al. Planejamento e execução de um carbonizador de casca de arroz, com base no reuso de resíduo do processo de beneficiamento de arroz. Disponível em: <www.ufpel. edu.br/cic/2006/arquivos/EN00102.rtf.> Acesso em: jan. 2011.

SÃO JOSÉ, A. R. Micropropagação de gipsofila (Gypsophila paniculata L. cv.Golan) e violeta-africana (Saintpaulia ionantha Wendl.). 2004. 99 f. Tese (Doutorado em Agronomia: Produção Vegetal) - Universidade Estadual Paulista, Faculdade de Ciências Agrárias e Veterinárias, Jabuticabal, 2004.

SILVA JÚNIOR, J. M. T.; GOMES, V. F. F.; MENDES FILHO, P. F. Atividade microbiana e desenvolvimento do melão cultivado sob diferentes proporções de pó de coco. Revista Caatinga, v. 19, n. 04, p. 369-376, 2006.

SORACE, M. et al. Substratos alternativos ao xaxim no cultivo do híbrido Cattleya intermedia X Hadrolaelia purpurata(Orchidaceae). Semina: Ciências Agrárias, v. 30, n. 04, p. 771-778, 2009.

TAKANE, R. J. Micropropagação e aclimatação de Gipsophila paniculata L.cv.BristolFairy "mosquitinho"(Cariophilaceae). 1997. 47 f. Dissertação (Mestrado em Fisiologia e Bioquímica de Plantas) - Escola Superior de Agricultura "Luis de Queiroz", Universidade de São Paulo, Piracicaba, 1997.

TAKANE, R. J.; YANAGISAWA, S. S.; PIVETTA, K. F. L. Cultivo moderno de orquídeas Cattleya e seus híbridos. Fortaleza, 2010. 179 p.

TAKANE, R. J.; PIVETTA, K. F. L.; YANAGISAWA, S. S. Cultivo técnico de cactos e suculentas ornamentais. Fortaleza, 2009. 168 p. 
YAMAKAMI, J. K. et al. Cultivo de Cattleya Lindley (Orchidaceae) em substratos alternativos ao xaxim. Acta Scientiarum: Agronomy, v. 28, n. 04, p. 523-526, 2006.

YAMAMOTO, L. Y. et al. Substratos alternativos ao xaxim no cultivo do híbrido primário Miltonia regnellii Rchb. f. X Oncidium concolor Hook. (Orchidaceae) Semina: Ciências Agrárias, v. 30, p. 1035-1042, 2009. Suplemento 1.
WOLCAN, S. M.; RONCO, L.; LORI, G. A. Podredumbres basales de Gypsophila paniculata (Caryophyllaceae): Agentes causales y su patogenicidad potencial sobre Dianthus caryophyllus (Caryophyllaceae). Boletín de la Sociedad Argentina de Botánica, v. 42, n. 03/04, p. 159-167, 2007.

ZONTA, E. P. MACHADO, A. A. SANEST - Sistema de Análise Estatística para Microcomputadores. Pelotas, RS: Universidade Federal de Pelotas, 1984 